\title{
Correction to: Examining the Role of Genetic Risk and Longitudinal Transmission Processes Underlying Maternal Parenting and Psychopathology and Children's ADHD Symptoms and Aggression: Utilizing the Advantages of a Prospective Adoption Design
}

\author{
Ruth Sellers ${ }^{1,2} \cdot$ Gordon T. Harold $^{2,3} \cdot$ Anita Thapar $^{2} \cdot$ Jenae M. Neiderhiser $^{4} \cdot$ Jody M. Ganiban $^{5} \cdot$ David Reiss $^{6}$. \\ Daniel S. Shaw ${ }^{7} \cdot$ Misaki N. Natsuaki ${ }^{8} \cdot$ Leslie D. Leve $^{9}$
}

Published online: 24 May 2021

(c) Springer Science+Business Media, LLC, part of Springer Nature 2021

Correction to: Behavior Genetics (2020) 50:247-262 https://doi.org/10.1007/s10519-020-10006-y

There is an error in the references for the measure of child ADHD symptoms at age 6 years.

Note that Child ADHD symptoms were assessed using items from the Conners' Abbreviated Parent Questionnaire (Conners 1973) \& items from the Revised DuPaul Child ADHD Rating Scale (DuPaul 1991; Thapar et al. 2000).

\section{References}

Conners CK (1973) Rating scales for use in drug studies with children. Psychopharmacol Bull [Special issue on children] 24-42

DuPaul GJ (1991) Parent and teacher ratings of ADHD symptoms: psychometric properties in a community-based sample. J Clin Child AdolescPsychol 20(3):245-253

Thapar A, Harrington R, Ross K, McGuffin P (2000) Does the definition of ADHD affect heritability? Child Adolesc Psychiatry 39(12):1528-1536

The original article can be found online at https://doi.org/10.1007/ s10519-020-10006-y.

Gordon T. Harold

gth25@cam.ac.uk

1 Department of Primary Care \& Public Health, Brighton \& Sussex Medical School, University of Sussex, Brighton, UK

2 Institute of Psychological Medicine and Clinical Neurosciences, School of Medicine, MRC Centre for Neuropsychiatric Genetics and Genomics, Cardiff University, Cardiff, UK

3 Faculty of Education, University of Cambridge, 184 Hills Road, Cambridge CB2 8PQ, UK

4 Department of Psychology, The Pennsylvania State University, University Park, PA, USA
Publisher's Note Springer Nature remains neutral with regard to jurisdictional claims in published maps and institutional affiliations.
Department of Psychology, George Washington University, Washington, DC, USA

6 Yale Child Study Center, Yale School of Medicine, New Haven, CT, USA

7 Department of Psychology, University of Pittsburgh, Pittsburgh, PA, USA

8 Department of Psychology, University of California, Riverside, CA, USA

9 Prevention Science Institute, University of Oregon, Eugene, OR, USA 